\title{
ENSINO DE LÍNGUAS NA CULTURA DIGITAL
}

\author{
LANGUAGES TEACHING IN CYBERCULTURE
}

\section{LA ENSEÑANZA DE LENGUAS EN LA CULTURA DIGITAL}

\author{
Tania Lucía Maddalena ${ }^{1}$ \\ Ana Sevilla-Pavón ${ }^{2}$ \\ Janaina Cardoso ${ }^{3}$
}

\section{Resumo}

Cada tecnologia que foi aparecendo na história trouxe novas possibilidades para o ensinoaprendizagem das línguas estrangeiras, desde os primeiros programas de rádio da metade do século $X X$, passando pelo cinema, televisão, computador até as experiências mais recentes mediadas pelo digital em rede como games, narrativas transmídia e realidade aumentada. $\mathrm{Na}$ cultura digital, as línguas se expandem com novas possibilidades de comunicação, interação e interatividade, permitindo conectar pessoas ao redor do mundo e potencializando a interculturalidade. $O$ presente artigo apresenta o dossiê de línguas na cultura digital, uma compilação de treze trabalhos de pesquisa e relatos de experiências pedagógicas, dois resumos de tese e dissertações e dois relatos de experiências literárias e culturais sobre os caminhos, tão diversos, do ensinar-aprender línguas na contemporaneidade.

\section{Abstract}

Throughout history, every new technology which emerged brought about new possibilities for foreign languages teaching and learning, from the first mid-20th century radio programmes, to cinema, television, computers and the most recent experiences mediated by digital

Submetido em: 20/12/2020 - Aceito em: 23/12/2020 - Publicado em: 24/12/2020

\footnotetext{
${ }^{1}$ Professora da Faculdade de Educação na Universidad Internacional de La Rioja (UNIR/Espanha).

${ }^{2}$ Professora Titular do IULMA/ Departamento de Filologia Inglesa e Alemana da Universitat de València (UV/Espanha).

${ }^{3}$ Professora Associada do Instituto de Letras na Universidade do Estado do Rio de Janeiro (UERJ/Brasil); Procientista (UERJ), Bolsista de Produtividade em Pesquisa (CNPq).
}

v. $4 \quad$ n.3


networks such as games, transmedia narratives and augmented reality. In digital culture, languages expand with new possibilities of communication, interaction and interactivity, connecting people around the world while enhancing interculturality. This article presents the dossier of languages in digital culture, a compilation of thirteen research projects and pedagogical experience reports, two summaries of thesis and dissertations and two literary and cultural experience reports on the very diverse ways of teaching and learning languages in contemporary times.

\section{Resumen}

Cada tecnología que apareció en la historia trajo nuevas posibilidades para la enseñanza de lenguas extranjeras, desde los primeros programas de radio de la mitad del siglo XX, pasando por el cine, la televisión, el ordenador hasta las experiencias más recientes mediadas por el lenguaje digital en red como los videojuegos, las narrativas transmedia y la realidad aumentada. En la cultura digital las lenguas se expanden con nuevas posibilidades de comunicación, interacción e interactividad, permitiendo conectar personas alrededor del mundo, potenciando la interculturalidad. Este artículo presenta el dossier sobre la enseñanza de lenguas en la cultura digital, una recopilación de trece trabajos de investigación y experiencias pedagógicas, dos resúmenes de tesis y trabajo final de Máster respectivamente, y dos experiencias literarias y culturales sobre los caminos, tan diversos, de enseñar y aprender lenguas en la contemporaneidad.

\section{REFLEXÕES PARA O INÍCIO DA VIAGEM}

No livro "Se Obama fosse africano" (2011), o escritor de Moçambique Mia Couto apresenta um pequeno ensaio chamado "A língua como viagem". Nele, argumenta que na atualidade as viagens perderam o sentido que tinham no passado, pois a humanidade consegue se deslocar muito rapidamente de uma ponta do mapa à outra, muitas vezes sem degustar os pequenos sabores e tempos que a viagem possui. Segundo o escritor, "a viagem, essa antiquíssima epopeia, com seus desconhecidos meandros, os seus ritmos e presságios, essa viagem morreu" (p. 174). Nesse entendimento de viagem, parte-se da ideia de que a viagem nos obriga a sermos outros, a nos deslocarmos para fora de nós, a viagem implica disponibilidade para sermos, também, apropriados pelo avesso. Por que escolhemos este ensaio para começar a apresentação deste dossiê de ensino de línguas? Porque após apresentar a ideia da viagem, Mia Couto conclui: "as línguas são as mais poderosas agências de viagens, os mais antigos e eficazes veículos de trocas, um veículo com que saímos de nós e viajamos para dentro de uma nova cidadania”. Assim, começar com esta inspiração é (re)afirmar que uma experiência formativa muito potente reside no aprendizado de uma língua, que vai além da decodificação de um 
código gramatical, pois as línguas abrem novos mundos e são poderosas agências de viagens.

Defendemos, assim, que o aprendizado de uma língua é também um processo de enculturação, reconhecemos que na cultura digital as línguas se expandem com novas possibilidades de comunicação, interação e interatividade, permitindo conectar pessoas ao redor do mundo, potencializando a interculturalidade e as possibilidades de formar(se) com outros.

A Educação e a Linguística Aplicada encaram hoje um cenário de desafios e possibilidades no que compete às línguas na cultura digital. Neste dossiê, apresentamos trabalhos que pretendem abrir um espaço de diálogo e reflexão sobre as práticas pedagógicas na aquisição das línguas no contexto de ensino formal (fundamental, médio e universitário) e, ao mesmo tempo, pensar as possibilidades que os novos fenômenos da cultura digital abrem para nossa área, aprendendo e praticando línguas para além da educação formal.

Um dos maiores desafios atuais para os professores e professoras de línguas estrangeiras tem a ver com a pandemia global trazida pela COVID-19 (PRADO CÓ, AMORIM; FINARDI, 2020, neste volume; FINARDI; SEVILLA-PAVÓN, em prensa). A pandemia Covid-19, iniciada no primeiro semestre de 2020, impactou e alterou muitas de nossas práticas sociais, impondo distanciamento social físico e aproximação virtual (HENRIQUE, 2020), obrigando muitas atividades de ensino-aprendizagem a migrarem para o modo remoto. Em seu artigo "Digital é o novo normal", Castells (2020) sugere que a atual pandemia mostrou o que já estava acontecendo, ou seja, já vivíamos na sociedade digital, embora não o tivéssemos aceito. As medidas de distância social impostas pela pandemia nos distanciaram fisicamente, embora tenham nos deixado virtualmente mais próximos, mostrando que a Internet pode servir tanto para conectar quanto para isolar / alienar indivíduos nesta nova realidade ou virtualidade.

Castells (2020) nos avisa que não haverá retrocesso nessa nova sociedade digital, pois o novo normal não será o que conhecíamos antes, mas uma nova realidade que também é virtual. Consciente da dificuldade de acesso às tecnologias digitais responsáveis pelo fosso digital entre quem as tem e quem não as tem, Castells afirma que na Espanha 91,4\% dos lares têm acesso à Internet através de um computador, e se contarmos as famílias que têm pelo menos um jovem, esses números sobem para 93,3\%. Enquanto isso, 97\% das pessoas possuem celular, $87 \%$ dos quais são smartphones, o que significa que possuem um computador com acesso à Internet no bolso ou na palma da mão. Já no caso do Brasil, de onde vem a maior parte dos respondentes de um dos estudos mais recentes (PRADO CÓ, AMORIM; FINARDI, 2020, neste volume), o Instituto Brasileiro de Geografia e Estatística (IBGE) mostrou que, em 2018, a Internet era utilizada em quase $80 \%$ dos lares, apresentando um crescimento considerável desde 2017, quando a taxa de acesso foi de 74,9\%. Ainda assim, é importante lembrar que grande parte desses domicílios com acesso à tecnologia digital estão localizados em centros urbanos. 
Embora a população total seja de aproximadamente 210 milhões, antes da pandemia ainda havia 46 milhões de brasileiros sem acesso à Internet, e isso, é claro, tem implicações significativas para a educação na cultura digital.

Com certeza, vivemos na cibercultura, mas será que todos têm o mesmo nível de acesso à Internet e à educação por meios digitais? Parece que a pandemia, o consequente distanciamento físico e a obrigação da adoção do ensino remoto emergencial (ERE) vêm demonstrar que estávamos/estamos bem distantes de uma equidade em relação à inclusão digital. No Brasil, a crise na saúde criou a situação que Mbembe (2016 apud LIBERALI, 2020) define como "necropolítica", ou seja, "o poder dos governos de decidir quem viverá e quem morrerá e de que forma os farão" (LIBERALI, 2020, p. 13). Consequentemente, ao adotar o ERE, pode-se criar a "necroeducação", que oferece apenas o igual a pessoas que se encontram em situações diferentes, muitas delas em contexto de fome (pela impossibilidade de trabalhar) e de morte (pela pandemia). Por exemplo, descobre-se que o acesso à Internet dependia muito de redes de wi-fi gratuitas, acessadas em lugares públicos. Com o isolamento, muitos perderam o acesso à rede, ou tiveram acesso restrito. Em muitos lares, só havia um dispositivo digital, muitas vezes somente o celular, mas toda a família teria que trabalhar e estudar compartilhando este dispositivo. Além disso, os professores são chamados a atuar remotamente, sem muito preparo. Enquanto, anteriormente, cursos a distância eram preparados com cuidado, adotando metodologias próprias e com alunos e professores que escolheram atuar na modalidade, o ERE está mais próximo do que Liberali (2020), citando Freire (1970/2018), define como "inédito viável". Viabilidade que antes não era percebida, solução de resposta imediata, com pouca reflexão e preparo. São múltiplas as dificuldades encontradas pelos professores e, no final de 2020, podemos ver como muitos se reinventaram para construir este "inédito viável" em tempos de pandemia.

Cabe aqui voltarmos à inspiração do ensaio de Mia Couto da "língua como viagem". O ano de 2020 trouxe um tempo de isolamento, de pouco contato físico, um ano no qual ficamos em casa sem viajar, mas, ao mesmo tempo, muitos de nós estivemos ensinando e aprendendo em conexão, e fizemos viagens (de autoconhecimento e de auto-reconhecimento) para o interior de nós mesmos. Apesar de todas as desigualdades, que aumentaram na pandemia, no complexo mundo que habitamos, reconhecemos que as redes digitais também nos possibilitaram viagens, abrindo novos mundos de partilha de sentidos, afetos e acolhimento. E as línguas, como grandes agências de viagens, também fluíram (e fluem) por essas redes digitais, convidando-nos a percorrer lugares, culturas e caminhar pelo universo da formação.

A presente edição da Revista Docência e Cibercultura (ReDoC), v.4, n.3, "ENSINO DE LÍNGUAS NA CULTURA DIGITAL" apresenta pesquisas, reflexões teóricas e experiências pedagógicas contidas em treze artigos, dois resumos de teses e dissertações e duas produções 
artísticas, literárias e culturais. Todas as produções avançam em diversas perspectivas sobre ensinar-aprender línguas na cibercultura. Apresentamos a seguir os artigos que compõem o dossiê reagrupados por temáticas.

\section{O ensino de línguas e a colaboração nos Ambientes Virtuais de Aprendizagem (AVA)}

Na primeira parte do dossiê, apresentamos três artigos que vão avançar em experiências de ensino de inglês em ambientes virtuais com propostas que incentivam a colaboração e interatividade entre os estudantes em diferentes experiências de ensino virtual.

O artigo "CYBERL@B AS AN OER FOR LEARNING ENGLISH THROUGH PRACTICE AND COLLABORATION": de Allen Quesada e Jenaro A. Díaz-Ducca, apresenta uma experiência de caso da Costa Rica, sobre a plataforma de acesso livre e o Open Education Resource (OER), Cyberl@b, que foi projetado para atender às necessidades e políticas educacionais públicas, é direcionado ao ensino do inglês como língua estrangeira na escola fundamental e média. Neste artigo, o Cyberl@b é descrito e analisado à luz dos conceitos de Laurillard de aprendizado através da prática (em inglês, LTP) e aprendizado através da colaboração (LTC). Com base nesses conceitos teóricos, foram extraídos critérios básicos para avaliar a plataforma como um recurso educacional que oferece interação multimídia, síncrona e assíncrona, feedback de pares e mentores, além de recursos para prática e colaboração nas seguintes habilidades macro e micro: ouvir, falar, ler, escrever, gramática, pronúncia e vocabulário. O estudo conclui que o Cyberl@b oferece oportunidades ricas de prática e colaboração de acordo com os princípios LTP e LTC para alunos de inglês nos níveis fundamental e médio na Costa Rica e em todo o mundo.

\section{O artigo INTERCÂMBIO VIRTUAL: CONTRIBUIÇÕES PARA A APRENDIZAGEM} DA LÍNGUA INGLESA DE ESTUDANTES DE LETRAS, de Cíntia Regina Lacerda Rabello, apresenta uma experiência de intercâmbio virtual para a aprendizagem de línguas estrangeiras. $\mathrm{O}$ artigo propõe um estudo de caso descritivo e de cunho etnográfico que teve como objetivo investigar como a participação em um intercâmbio virtual (O'DOWD, 2018) pode contribuir para a aprendizagem da língua inglesa e o desenvolvimento da competência comunicativa de estudantes de Letras em uma universidade federal brasileira. A pesquisa tem como contexto o projeto International Virtual Exchange (IVE), desenvolvido pelo Mororan Institute of Technology, no Japão, que utiliza a plataforma Moodle para as interações entre estudantes universitários de cursos de inglês como língua estrangeira em diferentes países na Ásia, Europa e América do Sul a partir do uso do inglês como língua franca. O estudo buscou identificar o engajamento e participação dos estudantes brasileiros no intercâmbio virtual e a sua percepção em relação às contribuições do intercâmbio para a aprendizagem da língua

\begin{tabular}{l|l} 
v. 4 & n.3
\end{tabular}


inglesa e o desenvolvimento da competência comunicativa. A aquisição de vocabulário e o uso de tecnologias digitais foram identificadas como principais contribuições do projeto para a aprendizagem da língua inglesa.

$O$ artigo REAL AND PERCEIVED AFFORDANCES OF IMMERSIVE VIRTUAL ENVIRONMENTS IN A LANGUAGE TEACHER-TRAINING CONTEXT: EFFECTS ON THE DESIGN OF LEARNING TASKS, de Maud Ciekanski, Carmenne Kalyaniwala e Virginie Privas-Bréauté, sugere que os ambientes virtuais imersivos (AVIs) oferecem possíveis soluções para transformar a imersão experiencial em competência e conhecimento de linguagem. Em vez de aceitar as considerações teóricas pelo valor de face, o presente estudo questiona a paixão, às vezes superficial, por AVIs, propondo um experimento prático desenvolvido em um treinamento de professores. Dezoito professores participantes de um curso de mestrado para formação de professores de inglês e espanhol (em pré-serviço ou em formação continuada) propõem cenários de ensino que integram AVIs a tarefas para o ensino e aprendizagem de línguas. A fim de compreender como os futuros professores de línguas fazem uso dessa nova tecnologia, os pesquisadores questionam como as "reais" possibilidades dos AVIs (extraídas de sua revisão de literatura) são percebidas pelos professores-participantes. Uma análise mista de onze cenários de aprendizagem revela esquemas de utilização que demonstram como os AVIs são "instrumentalizados" (RABARDEL, 1995) para uso e percebidos por professores-participantes como um suporte potencial para a aprendizagem de línguas e culturas. Os resultados abrem espaço para questões que discutem se os AVIs são de fato um recurso complementar dentre outros recursos autênticos usados na sala de aula e se levam a uma renovação das práticas de aprendizagem de línguas.

\section{Práticas e pesquisas sobre o ensino de línguas na pandemia}

O dossiê também inclui dois artigos que trabalham com o desafio de narrar o tempo presente e as dificuldades encontradas ao longo do 2020 pelos professores de línguas que tiveram que adaptar suas aulas à modalidade de ensino remoto. São dois artigos que articulam importantes reflexões e levantamentos:

No artigo ENSINO DE LÍNGUAS EM TEMPOS DE PANDEMIA: EXPERIÊNCIAS COM TECNOLOGIA EM AMBIENTES VIRTUAIS Elisa Prado Có, Gabriel Brito Amorim, Kyria Rebeca Finardi refletem sobre o ensino de línguas em contextos virtuais a partir de experiências vividas por professores de línguas durante a pandemia. Um questionário online com 14 perguntas, compartilhado nas redes sociais foi respondido por 64 professores de línguas, 4 dos quais participaram de uma entrevista no formato de roda de conversa após terem respondido o questionário. O método de análise é misto com dados quantitativos e qualitativos. 
A análise quantitativa mostrou que a grande maioria dos respondentes usou tecnologias digitais para dar aula no formato remoto tanto de forma síncrona quanto assíncrona. Os dados sugerem que nem todos os professores se sentem preparados para trabalhar nessa modalidade, revelando falta de apoio, capacitação ou formação por parte de instituições no sentido de viabilizar o ensino no formato remoto. A análise qualitativa sugeriu que os professores têm uma postura negativa em relação ao ensino remoto emergencial em virtude da falta de preparo para essa modalidade. De maneira geral, os resultados do estudo sugerem que a emergência da situação causou um impacto negativo nos professores em relação ao uso de tecnologias digitais no ensino remoto emergencial devido ao despreparo e falta de apoio institucional. Entretanto, os dados sugerem que após a pandemia e com o devido preparo e apoio, algumas dessas tecnologias digitais serão incorporadas nas práticas pedagógicas em abordagens híbridas, que representam uma tendência e possibilidade real para o ensino de línguas no contexto póspandemia.

O artigo ENSINO DE LÍNGUA INGLESA E CULTURA DIGITAL EM TEMPOS DE PANDEMIA: O DESAFIO DE SUPERAR O CURTO ESPAÇO DE TEMPO ENTRE O DITO E O VIVIDO de Carlos Henrique Andrade de Sousa, Francisco Thiago Chaves de Oliveira, Elcimar Simão Martins apresenta os desafios para a implantação do ensino remoto de modo emergencial durante a pandemia, o presente texto objetiva compreender o ensino e a aprendizagem de língua inglesa mediados pelas tecnologias digitais no contexto da pandemia do Covid-19. De abordagem qualitativa, metodologicamente o estudo se utilizou das tecnologias digitais de informação e da comunicação para coletar os dados. Assim, foram analisadas as respostas de quarenta e quatro estudantes de língua inglesa do Centro Cearense de Idiomas - CCI. Para tanto, foi utilizado um questionário online disponibilizado no Google Formulários. $\mathrm{O}$ estudo contou ainda com a participação do professor dos referidos discentes, que registrou suas impressões por meio de um diário de formação digital. O conjunto de dados revela que, inicialmente, as aulas foram paralisadas e os estudantes ficaram na ansiedade da retomada. Com o ensino remoto implantado de modo emergencial surgiram desafios como: o estudo e o trabalho nas limitações do ambiente familiar, desconsiderando aspectos e situações pessoais, profissionais e contextuais que influenciam discentes e docentes; a baixa qualidade de equipamentos tecnológicos de boa parte dos discentes para a efetivação das atividades; a constatação de que a formação tecnológica dos docentes não seria suficiente para as exigências do ensino remoto no CCI, desencadeando um movimento de solidariedade entre os pares. Conclui-se que, a despeito das dificuldades enfrentadas, do desgaste físico e mental, os discentes apresentam esperança, satisfação e tranquilidade em relação à vida pessoal e estudantil e os docentes conseguiram motivar e acompanhar os estudantes nesse processo.

Jogos virtuais, videogames, recursos audiovisuais e aplicativos em experiências de ensinoaprendizagem de línguas 


\section{O artigo PRAGMATICS: WHY USE AUDIOVISUAL INPUT IN SECOND AND} FOREIGN LANGUAGE LEARNING CONTEXTS? de Manuel Rodríguez Peñarroja, apresenta: o ensino e a aquisição de pragmática em contextos de aprendizagem de segunda língua e língua estrangeira foram tradicionalmente reduzidos a exemplos de diálogos descontextualizados e imagens estáticas dos livros didáticos, quase sem efeitos na competência comunicativa dos alunos. Este artigo descreve a lógica do ensino de pragmática, uma vez que se tornou de importância essencial, conforme especificado em diferentes paradigmas de proficiência em linguagem, ou seja, o QECR. Assim, a atenção está centrada no uso de materiais audiovisuais como uma rica fonte de entrada utilizada para esse fim. Com isso em mente, é feita uma revisão de estudos que avaliam a validade da linguagem utilizada em gêneros audiovisuais. Além disso, é apresentada uma visão geral de sua aplicabilidade e efeitos como parte dos currículos da educação geral e no ensino de uma segunda língua e língua estrangeira. Os estudos revisados relataram resultados vantajosos gerais ao usar este tipo de input (insumo) para diferentes objetivos instrucionais e, mais especificamente, com fins de aquisição de pragmática.

\section{O artigo "PRESS START PARA APRENDER: VIDEOGAMES E APRENDIZAGEM DE} LÍNGUA INGLESA" de Talisson Subtil Vogelmann, Marcos Guilherme de Souza Ferraz e Andressa Brawerman-Albini parte da ideia de que nos processos de aquisição e aprendizado de segunda língua (L2), Krashen (1981) diferencia entre um processo espontâneo e um processo formal de aprendizado da língua, respectivamente. Dentro destes processos, encontram-se pessoas que afirmam que seu conhecimento de L2 vem única, ou primariamente, do seu contato com videogames. Esse tipo de afirmação levanta questionamentos acerca das diferenças entre o aprendizado formal e o processo de aquisição informal. Muitas dessas discussões destacam as relações entre a experiência propiciada pelos videogames e as motivações do aprendiz. Podemos entender esse elemento motivador dos games no ensino de L2 ao olharmos as ideias de Gee (2003) sobre como os videogames conectam a linguagem a significados específicos e contextualizados. No entanto, é necessário ressaltar que a língua se divide em diferentes habilidades. Sendo assim, os autores apresentam uma pesquisa que busca lançar um olhar sobre como esses contextos de aprendizados, ensino formal e videogames, conversam com cada uma dessas habilidades linguísticas. Propondo um questionário nos moldes sugeridos por Dörnyei (2001), para aprendizes que afirmam ter tido experiência com os dois contextos, esta pesquisa tem por objetivo entender quais habilidades foram mais favorecidas por cada contexto. Os resultados mostram que algumas habilidades, como o reading, foram apontadas como mais produtivas através dos videogames, enquanto outras, como o writing, apareceram como mais produtivas dentro do ensino formal. Por fim, o trabalho procura estimular discussões sobre de quais maneiras e em quais momentos utilizar videogames no processo de ensino de inglês pode ser benéfico. 
No artigo ANÁLISE DO DISCURSO E SEGUNDA LÍNGUA: PORTAL 2 NO ENSINO DE VOCABULÁRIO a autora Fabielle Rocha Cruz reflete sobre as aulas de segunda língua, nas quais é muito comum que o professor foque no vocabulário a ser aprendido e o aluno, muitas vezes, carece de contexto e de explicações sobre determinadas palavras ou expressões que têm um sentido muito único ou peculiar, que se conectam com a identidade do falante. Assim, utilizar meios que tragam a língua contextualizada, de modo que o aluno possa utilizar recursos da análise do discurso (AD), como o ethos, para melhor entender a escolha das palavras, é um atrativo. Através de uma revisão bibliográfica dos estudos de $\mathrm{AD}$ e de ethos, bem como uma pesquisa do tipo exploratória, o presente artigo propõe-se a analisar a possiblidade de utilizar os jogos digitais, mais especificamente o jogo Portal 2, para mostrar a importância das escolhas lexicais. Através de um quadro com frases do jogo escolhido, apontase a conexão entre entonação e identidade da personagem escolhida para adequar e contextualizar os recursos. Por fim, apresenta-se os resultados, observando-se a faixa etária e o conteúdo que faz parte do jogo, entendendo-se que o professor não perde seu papel para o jogo, mas torna-se mediador da aprendizagem.

O artigo TECNOLOgias Digitais Móveis, PRATICANTES DE LÍNGUA INGLESA E UMA PROPOSTA PEDAGÓGICA PARA O USO DE APPS de Luciana de Jesus Lessa Censi e Rosane Meire Vieira de Jesus, apresenta as relações estabelecidas entre tecnologias e aplicativos móveis e os processos de ensino-aprendizagem de língua inglesa por praticantes desse idioma, do $7^{\circ}$ ao $9^{\circ}$ ano do ensino fundamental de uma escola pública. Ao trazer à tona as vozes desses praticantes, objetivou-se entender como se viabiliza outras possibilidades para a educação linguística na cultura digital e cibercultura. Uma vez que os praticantes se caracterizam por desenvolver táticas e criações para subverter situações da realidade que lhes é dada, foram utilizados grupos de diálogo na perspectiva do estudo qualitativo e de uma abordagem interpretativa a partir de Gadamer (1999). Os diálogos evidenciaram implicações em torno do tema e alguns fundamentos que podem orientar caminhos pedagógicos para o uso de aplicativos nos processos de ensinoaprendizagem de inglês, sobretudo, no cotidiano escolar.

\section{Multiletramentos e formação de professores e ensino de línguas}

O trabalho EMPODERAMENTO POR MEIO DE MULTILETRAMENTOS: UM ESTUDO DE CASO INTERATIVO EM AMBIENTE INFOPOBRE, de Layse Henriques da Costa Kitagawa, Bruna Renova Varela Leite, Cláudio Ricardo Corrêa, descreve um trabalho que teve como objetivo apresentar atividades em sala de aula com foco em multiletramentos (COPE, KALAZANTZIS, 2000), dado pelo acesso a diversos gêneros textuais em suportes digitais, enfocando o tema do empoderamento feminino. A metodologia adotada foi da 
pesquisa-ação participante (BRANDÃO, STRECK, 2006), tendo como dispositivo gerador de dados a produção escrita dos estudantes, a fim de propiciar interatividade (SILVA, 2002). Os resultados obtidos demonstram que, ainda que em um ambiente infopobre, apoiados por uma pedagogia multiletrada e multissemiótica, os educandos conseguiram expressar um pensamento crítico acerca do feminismo, e puderam se apropriar de marcas tipográficas oriundas dos meios digitais. Conclui-se que no ensino de línguas adicionais há espaço para participação democrática e crítica dos alunos, que puderam construir conhecimento sobre feminismo, e também para ensino com tecnologias, ainda que as ferramentas sejam escassas.

O artigo PEDAGOGia dOS MULTILETRAMENTOS NAS AULAS DE LÍNGUA INGLESA: DIÁLOGOS EM EXPERIÊNCIA EM ESTÁGIO, de Carolina Fernanda Cunha Campos e Mariana Lettieri Ferreira, apresenta um estudo qualitativo de caráter exploratório que integra uma experiência de estágio da pesquisadora e estagiária licencianda em língua inglesa, primeira autora deste artigo, realizada em uma escola municipal da cidade de São Paulo. A proposta de estágio envolveu-se nos pressupostos teóricos da pedagogia dos multiletramentos, conforme proposta pelo Grupo de Nova Londres em 1996, além de também terem sido encontrados pontos de convergência com a pedagogia da autonomia conforme proposta por Freire (1996). A vivência formativa aqui relatada, uma sequência de quatro aulas, possibilitou a criação de atividades relevantes para os alunos, pautadas na estrutura da sala de aula, com discussões sobre suas necessidades e análise de diferentes cenários. Além disso, a experiência possibilitou às autoras debates sobre a própria pedagogia dos multiletramentos, a pedagogia da autonomia, as demandas do ensino de inglês na escola e os efeitos do estágio na formação de professores.

FORMAÇÃO CONTINUADA DE PROFESSORES: CONTRIBUIÇÕES DA OFICINA
PEDAGÓGICA PARA A APRENDIZAGEM DO SOFTWARE SCRATCH, de Viviane da Costa Bastos, apresenta as ações realizadas pelos professores de inglês que atuam em uma Escola Pública Municipal Bilíngue (português/inglês) na cidade do Rio de Janeiro e participaram de uma oficina presencial para a aprendizagem do software Scratch como ferramenta que contribui para a atuação pedagógica. O trabalho, então, situa-se em uma pesquisa qualitativa com abordagem descritiva e interpretativista (GIL, 1999), no qual os dados foram gerados a partir de observações sistemáticas e participantes (RUDIO, 1985) durante a realização da oficina. Os resultados indicam que o software Scratch é um programa que possibilita a criação de espaços de aprendizagem e pode contribuir para a reflexão, o entrelaçamento dos saberes da formação inicial com os da formação continuada, a colaboração e novas práticas do professor.

O artigo TECNOLOGIAS EDUCACIONAIS NO ENADE DO CURSO DE LICENCIATURA EM LETRAS: ANÁLISE DE 2005 A 2017, de Daíne Cavalcanti da Silva 
e Glaucia da Silva Brito, apresenta um estudo que teve como foco analisar como são avaliados os professores de língua em formação, no que diz respeito às tecnologias educacionais, nas provas do ENADE (Exame Nacional do Ensino Médio) para o curso de Licenciatura em Letras, considerando o contexto da cibercultura. O objetivo do ENADE é verificar o rendimento dos alunos em comparação às diretrizes curriculares do curso. O corpus foi composto dos documentos publicados pelo INEP para a realização das avaliações e das provas aplicadas aos estudantes, nos anos de 2005 a 2017, bem como as diretrizes que norteiam o curso. Foi realizada a análise de conteúdo do corpus a partir das categorias criadas, considerando a metodologia proposta por Bardin (2016). Confirmou-se a existência de questões que abordam a temática tecnologias educacionais e que ao longo dos anos houve uma preocupação em avaliar o entendimento dos professores de língua em formação para além da inserção de equipamentos nos ambientes de ensino. Percebeu-se ainda um aumento quantitativo e qualitativo ao longo dos anos em relação às questões aplicadas; temas foram incluídos e foi exigido dos licenciandos uma reflexão sobre a relação entre conteúdos e metodologias no ensino de línguas concernente às tecnologias educacionais

\section{Seção resumos de Teses e Dissertações}

Nesta sessão temos o resumo de tese AQUISIÇÃo DE INGLÊS COMO LÍNGUA ADICIONAL ATRAVÉS DA MESCLAGEM CONCEPTUAL EM VIDEOGAMES DE RPG de Luciana Braga Carneiro Leão-Junqueira, que objetivou analisar o conhecimento lexical em inglês como língua adicional desenvolvido através da formação e expansão de modelos cognitivos idealizados e frames na mente de jogadores durante a leitura extensiva propiciada por jogos de videogame de RPG. Como resultados, foram apresentadas propostas de representação dos modelos cognitivos idealizados e frames (FAUCONNIER, 1994) desenvolvidos pelos participantes durante o processamento cognitivo do vocabulário em inglês apresentado durante a fase jogada, bem como discussões sobre os processos que levaram aos seus desenvolvimentos, em especial as estratégias de aprendizagem (OXFORD, 1999; 2017; CARDOSO, 2016) empregadas pelos participantes, a mesclagem conceptual (FAUCONNIER, 1997) entre modelos cognitivos idealizados em língua materna e em inglês como língua adicional durante o jogo, e o grau de contribuição da multimodalidade (KRESS; VAN LEEUWEN, 1996; HEMAIS, 2015) na mesclagem conceptual desses modelos cognitivos idealizados. A premissa da presente pesquisa era a de que a redundância de informações provida pela multimodalidade presente nos jogos de videogame de RPG permitiria a formulação de hipóteses de modelos cognitivos idealizados na língua adicional a partir de modelos já existentes em língua materna. Tal premissa foi corroborada pelos dados analisados, através dos quais foi possível concluir que as hipóteses elaboradas pelos aprendizes são levantadas através 
de estratégias de aprendizagem relacionadas ao uso da multimodalidade, testadas pelos mesmos através do processo de mesclagem conceptual e, consequentemente, comprovadas ou reformuladas, desencadeando o aprendizado de inglês como língua adicional.

E o resumo da dissertação APRENDIZAGEM DE SEGUNDA LÍNGUA POR MEIO DA EDUCAÇÃO ONLINE ABERTA: O USO DE TECNOLOGIAS DIGITAIS, GAMIFICAÇÃO E AUTODIDATISMO NO PROCESSO DE AQUISIÇÃO LINGUÍSTICA, de Cláudio Ricardo Corrêa, que aborda como ocorre o ensino/aprendizagem de segunda língua - por meio da educação online aberta - tendo como viés o uso de tecnologias digitais (em especial as de acesso à internet). Entre os temas abordados estão: gamificação, tecnologias de informação e comunicação (TICs), ambientes virtuais de aprendizagem (AVAs), educação a distância (EAD), cibercultura, autodidatismo, autonomia, pensamento crítico, autoria, inclusão e democratização do acesso à aprendizagem. Para isso optou-se pelos cursos, aplicativos e sites de ensino/aprendizagem de segunda língua gratuitos. Trata-se de uma pesquisa qualitativa para a qual foram selecionados participantes adultos - falantes nativos de língua portuguesa, que não tiveram instrução formal da língua-alvo -, que fizeram testes de nivelamento comparativos (iniciais e finais), com o propósito de averiguar a aprendizagem. $\mathrm{O}$ curso-base escolhido para os participantes foi o Duolingo. Também foram agregados outros meios digitais de educação aberta, disponíveis para prática, interação, aperfeiçoamento e desenvolvimento de competência linguística.

\section{Seção Produções Artísticas, Literárias e Culturais}

A produção de conhecimentos na cultura é, para nós, uma fonte de saberes-fazeres que inspiram novas práticas e somam conhecimentos potentes ao campo da formação continua de professores e estudantes. No dossiê de línguas na cultura digital contamos com dois artigos que relatam experiências formativas em diversas linhas e inspiram novos e potentes debates na circulação de conhecimentos. O artigo ANTENA ARGENTA: RELATO DE USOS DAS REDES SOCIAIS PARA DIFUSÃO DE LITERATURA ARGENTINA NO BRASIL de Davidson De Oliveira Diniz, apresenta um relato de uso das redes sociais na produção e difusão de conteúdos e atividades relacionadas à página ANTENA ]A[ RGENTA - canal de literatura argentina no Brasil. Trata-se de um projeto elaborado com a intenção de produzir material próprio, bem como divulgar eventos relacionados à circulação da literatura argentina no Brasil e da literatura brasileira na Argentina. E com isso pensar as dinâmicas atuais dos dispositivos de circulação bilateral entre nosso binômio. 
E por último, o artigo "INGLÊS E NEGRITUDE: Uma abordagem diferente no ensino de línguas" de Monique Carvalho narra a experiência em primeira pessoa do Ifé English Course, assim como tantos grupos negros, nasce da necessidade da população negra de acesso à melhores condições de trabalho, oportunidades de empreendedorismo e vida acadêmica através do domínio do inglês. O curso é um grupo organizado de pessoas trabalhando pelo mesmo objetivo, mas se torna algo maior a cada ano que passa. Com os elementos das várias culturas negras espalhadas ao redor do globo, os participantes trocam conhecimentos não só sobre a língua, mas também saberes que foram tiramos das culturas negras no decorrer dos séculos e que hoje os fortalecem. Neste texto, Monique Carvalho conta um pouco sobre como o curso começou e que direção está tomando desde então.

Desejamos a todos uma boa leitura e ótimas reflexões.

\section{REFERÊNCIAS}

BARDIN, Laurance. Análise de conteúdo. São Paulo: Edições 70, 2016.

BASTOS, Viviane da Costa. FORMAÇÃO CONTINUADA DE PROFESSORES: CONTRIBUIÇÕES DA OFICINA PEDAGÓGICA PARA A APRENDIZAGEM DO SOFTWARE SCRATCH. Revista Docência e Cibercultura, v. 4, n. 3, set-dez, 2020, p. 291-307. DOI: https://doi.org/10.12957/redoc.2020.53174

BRANDÃO, Carlos Rodrigues; STRECK, Danilo Romeu. (Orgs). Pesquisa participante: a partilha do saber. Aparecida - SP: Ideias \& Letras, 2006.

CAMPOS, Carolina Fernanda Cunha; FERREIRA; Mariana Lettieri. PEDAGOGIA DOS MULTILETRAMENTOS NAS AULAS DE LÍNGUA INGLESA: DIÁLOGOS EM EXPERIÊNCIA EM ESTÁGIO. Revista Docência e Cibercultura, v. 4, n. 3, set-dez, 2020, p. 266-290. DOI: https://doi.org/10.12957/redoc.2020.52897

CASTELLS, Manuel. O digital é o novo normal. Disponível em: https://www.fronteiras.com/artigos/odigital-e-o-novo-normal. Acesso em 21 de dez. de 2020.

CARDOSO, Janaína da Silva. Estratégias de aprendizagem: eficácia e autonomia na compreensão oral. Saarbrücken, Alemanha: Novas Edições Acadêmicas, 2016.

CENSI, Luciana de Jesus; JESUS, Lessa Rosane Meire Vieira de. TECNOLOGIAS DIGITAIS MÓVEIS, PRATICANTES DE LÍNGUA INGLESA E UMA PROPOSTA PEDAGÓGICA PARA O USO DE APPS. Revista Docência e Cibercultura, v. 4, n. 3, set-dez, 2020, p. 228-247. DOI: https://doi.org/10.12957/redoc.2020.53427

CIEKANSKI, Maud; KALYANIWALA, Carmenne; MOLLE, Nicolas; PRIVAS-BRÉAUTÉ, Virginie. REAL AND PERCEIVED AFFORDANCES OF IMMERSIVE VIRTUAL ENVIRONMENTS IN A LANGUAGE TEACHER- 
TRAINING CONTEXT: EFFECTS ON THE DESIGN OF LEARNING TASKS. Revista Docência e Cibercultura, v. 4, n. 3, set-dez, 2020, p. 83-111. DOI: https://doi.org/10.12957/redoc.2020.56752

CÓ, Elisa Prado; AMORIM, Gabriel Brito; FINARDI, Kyria Rebeca. ENSINO DE LÍNGUAS EM TEMPOS DE PANDEMIA: EXPERIÊNCIAS COM TECNOLOGIA EM AMBIENTES VIRTUAIS. Revista Docência e Cibercultura, v. 4, n. 3, set-dez, 2020, p. 112-140. DOI: https://doi.org/10.12957/redoc.2020.53173

CORRÊA, Cláudio Ricardo. APRENDIZAGEM DE SEGUNDA LÍNGUA POR MEIO DA EDUCAÇÃO ONLINE ABERTA: O USO DE TECNOLOGIAS DIGITAIS, GAMIFICAÇÃO E AUTODIDATISMO NO PROCESSO DE AQUISIÇÃO LINGUÍSTICA. Revista Docência e Cibercultura, v. 4, n. 3, set-dez, 2020, p. 399-410. DOI: https://doi.org/10.12957/redoc.2020.54614

COPE, Bill; KALANTZIS, Mary. (Eds.). Multiliteracies: Literacy Learning and the Design of Social Futures. London: Routledge, p. 121-234, 2000.

COUTO, Mia. E se Obama fosse africano? São Paulo: Companhia das Letras, 2011.

CRUZ, Fabielle Rocha. ANÁLISE DO DISCURSO E SEGUNDA LÍNGUA: PORTAL 2 NO ENSINO DE VOCABULÁRIO. Revista Docência e Cibercultura, v. 4, n. 3, set-dez, 2020, p. 213-227. DOI: https://doi.org/10.12957/redoc.2020.53087

DINIZ; Davidson De Oliveira. ANTENA ARGENTA: RELATO DE USOS DAS REDES SOCIAIS PARA DIFUSÃO DE LITERATURA ARGENTINA NO BRASIL. Revista Docência e Cibercultura, v. 4, n. 3, set-dez, 2020, p. 461-468. DOI: https://doi.org/10.12957/redoc.2020.54294

DÖRNYEI, Z. Motivational strategies in the language classroom. Cambridge: CUP, 2001.

FAUCONNIER, Gilles. Mental spaces. Cambridge: Cambridge University Press, 1994.

FAUCONNIER, Gilles. Mappings in thought and language. Cambridge: Cambridge University Press, 1997.

FINARDI, Kyria Rebeca; SEVILLA-PAVÓN, Ana. (em prensa). Pandemic language teaching: insights from Brazilian and international teachers on the pivot to emergency remote instruction. Em: García Laborda, Jesús; Montaner Villalba, Salvador (Eds.): Language \& Education Special issue: Current trends in ELT educational communication during crises. Language \& Education.

FREIRE, Paulo. Pedagogia da autonomia. Sao Paulo: Paz e Terra, 2004

FREIRE, Paulo. Pedagogia do oprimido. 66a ed. Rio de Janeiro / São Paulo: Paz e Terra, 2018.

GADAMER, Hans-Georg. Verdade e método I: traços fundamentais de uma hermenêutica filosófica. Tradução de Flávio Paulo Meurer. 3. ed. Petrópolis: Vozes, 1999. GEE, James Paul. What video games have to teach us about learning and literacy. 1a ed. New York: Palgrave/St. Martin's, 2003.

GIL, Antonio Carlos. Como elaborar projetos de pesquisa. São Paulo: Atlas, 1999.

v. $4 \quad$ n.3

p. 28 
HEMAIS, Barbara Jane Wilcox. Práticas pedagógicas no ensino de inglês: integrando gêneros discursivos e multimodalidade. In: HEMAIS, Barbara Jane Wilcox (Org.). Gêneros discursivos e multimodalidade: desafios, reflexões e propostas no ensino de inglês. Campinas, SP: Pontes Editores, 2015, p. 19-34.

HENRIQUE, Trazíbulo. COVID-19 e a internet (ou estou em isolamento social físico). Interfaces Científicas - Humanas e Sociais, Aracaju, v. 8, n.3, p. 173-176, 2020. Disponível em: <https://bit.ly/2KMPtG5>. Acesso em: 28 abr. 2020.

KITAGAWA, Layse Henriques da Costa; LEITE, Bruna Renova Varela; CORRÊA, Cláudio Ricardo. EMPODERAMENTO POR MEIO DE MULTILETRAMENTOS: UM ESTUDO DE CASO INTERATIVO EM AMBIENTE INFOPOBRE. Revista Docência e Cibercultura, v. 4, n. 3, set-dez, 2020, p. 248-265. DOI: https://doi.org/10.12957/redoc.2020.53337

KRASHEN, S. Second language acquisition and second language learning. Oxford: Pergamon Press, 1981.

KRESS, Gunther.; VAN LEEUWEN, Theo. Reading images: the grammar of visual design. New York: Routledge, 1996.

LEÃO-JUNQUEIRA, Luciana Braga Carneiro. AQUISIÇÃO DE INGLÊS COMO LÍNGUA ADICIONAL ATRAVÉS DA MESCLAGEM CONCEPTUAL EM VIDEOGAMES DE RPG. Revista Docência e Cibercultura, v. 4, n. 3, set-dez, 2020, p. 387-398. DOI: https://doi.org/10.12957/redoc.2020.54153

LIBERALI, Fernanda. Construir o inédito viável em meio a crise de Coronavírus - lições que aprendemos, vivemos e propomos. In LIBERALI, F.; FUGA, V.; DIEGUES, U.; CARVALHO, M. Educação em tempos de pandemia: brincando com um mundo possível. Campinas: Pontes, 2020.

MBEMBE, Achille. Necropolítica. Artes e Ensaios, n. 32, 2016, p.122-151. Disponível em: https://revistas.ufrj.br/index.php/ae/article/view/8993/7169. Acesso em: 21 de dez. de 2020.

O'DOWD, R. From telecollaboration to virtual exchange: state-of-the-art and the role of UNICollaboration in moving forward. Journal of Virtual Exchange, 1, 2018. p. 1 - 23. Disponível em: https://www.researchgate.net/publication/324729746 From telecollaboration to virtual exchang e state-of-the-art and the role of UNICollaboration in moving forward Acesso em: 19 ago. 2020.

OXFORD, Rebecca L. Anxiety and the language learner: new insights. In: ARNOLD, J. (Ed.). Affect in language learning. Cambridge: Cambridge University Press, 1999, p. 50-67.

OXFORD, Rebecca L. Teaching and researching language learning strategies: self-regulation in context. 2a ed. New York \& London: Routledge, 2017.

QUESADA, Allen; DÍAZ-DUCCA, Jenaro A. CYBERL@B AS AN OER FOR LEARNING ENGLISH THROUGH PRACTICE AND COLLABORATION. Revista Docência e Cibercultura, v. 4, n. 3, set-dez, 2020, p. 31-57. DOI: https://doi.org/10.12957/redoc.2020.51666 
RABARDEL, Pierre. Les hommes et les technologies; approche cognitive des instruments contemporains. Paris: Armand Colin, 1995. ffhal-01017462

RABELLO, Cíntia Regina Lacerda. INTERCÂMBIO VIRTUAL: CONTRIBUIÇÕES PARA A APRENDIZAGEM DA LÍNGUA INGLESA DE ESTUDANTES DE LETRAS. Revista Docência e Cibercultura, v. 4, n. 3, set-dez, 2020, p. 58-82. DOI: https://doi.org/10.12957/redoc.2020.53886

RODRÍGUEZ-PEÑARROJA, Manuel. PRAGMATICS: WHY USE AUDIOVISUAL INPUT IN SECOND AND FOREIGN LANGUAGE LEARNING CONTEXTS? Revista Docência e Cibercultura, v. 4, n. 3, set-dez, 2020, p. 161-178. DOI: https://doi.org/10.12957/redoc.2020.53890

RUDIO, Franz Victor. Introdução ao Projeto de Pesquisa Científica. Petrópolis: Editora Vozes, 1985.

SILVA, Daíne Cavalcanti da; BRITO, Glaucia da Silva. TECNOLOGIAS EDUCACIONAIS NO ENADE DO CURSO DE LICENCIATURA EM LETRAS: ANÁLISE DE 2005 A 2017. Revista Docência e Cibercultura, v. 4, n. 3, set-dez, 2020, p. 308-340. DOI: https://doi.org/10.12957/redoc.2020.53858

SILVA, Marco. Sala de Aula Interativa. 3a ed. Rio de Janeiro: Quartet, 2002.

SOUSA, Carlos Henrique Andrade de; OLIVEIRA, Francisco Thiago Chaves de; MARTINS, Elcimar Simão. ENSINO DE LÍNGUA INGLESA E CULTURA DIGITAL EM TEMPOS DE PANDEMIA: O DESAFIO DE SUPERAR O CURTO ESPAÇO DE TEMPO ENTRE O DITO E O VIVIDO. Revista Docência e Cibercultura, v. 4, n. 3, set-dez, 2020, p. 141-160. DOI: https://doi.org/10.12957/redoc.2020.53901

VOGELMANN, Talisson Subtil; FERRAZ, Marcos Guilherme de Souza; BRAWERMAN-ALBINI, Andressa. PRESS START PARA APRENDER: VIDEOGAMES E APRENDIZAGEM DE LÍNGUA INGLESA. Revista Docência e Cibercultura, v. 4, n. 3, set-dez, 2020, p. 179-212. DOI: https://doi.org/10.12957/redoc.2020.52630

\section{Agradecimentos}

A autora 2 agradece ao Ministério Ciência, Inovação e Universidades do Governo da Espanha por apoio à pesquisa no formato de projeto: Virtual exchange for learning and competence development in EMI classrooms (VELCOME, ref: RTI2018-094601-B-100), para o período 2018-2021.

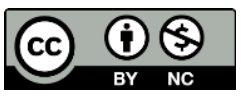

Este é um artigo de acesso aberto distribuído sob os termos da Licença Creative Commons Atribuição Não Comercial-Compartilha Igual (CC BY-NC- 4.0), que permite uso, distribuição e reprodução para fins não comerciais, com a citação dos autores e da fonte original e sob a mesma licença. 